

\title{
Diálogos sobre sexualidade na família: reflexões a partir do discurso de meninas
}

\author{
Dialogues about sexuality in the family: reflections from the discourse of girls
}

Sabrina Dal Ongaro Savegnago ${ }^{[a]}$, Dorian Mônica Arpini ${ }^{[b]}$

\footnotetext{
a] Psicóloga, mestre em Psicologia pela Universidade Federal de Santa Maria (UFSM), doutoranda do Programa de Pós-Graduação em Psicologia da Universidade Federal do Rio de Janeiro, Rio de Janeiro, RJ - Brasil, e-mail: sabrinadsavegnago@gmail.com

${ }^{[b]}$ Psicóloga, professora associada do Departamento de Psicologia e do Programa de Pós-Graduação em Psicologia da Universidade Federal de Santa Maria, Santa Maria, RS - Brasil, e-mail: monica.arpini@gmail.com
}

Recebido: $27 / 08 / 2012$ Received: 08/27/2012

Aprovado: $11 / 10 / 2012$ Approved: 10/11/2012

\section{Resumo}

Este estudo objetivou conhecer como se apresenta a temática da sexualidade no contexto familiar de adolescentes de grupos populares. Realizaram-se grupos focais com meninas de duas escolas de ensino fundamental de uma cidade do interior do Rio Grande do Sul. Os dados foram analisados através da Análise de Conteúdo. Os resultados revelam que apesar das dificuldades existentes para se abordar a temática da sexualidade, quando este assunto é tratado, geralmente são as mães que o fazem. As adolescentes entendem que as mães estão mais disponíveis para conversar com as meninas, enquanto os pais têm mais facilidade com os meninos. 0 uso da camisinha é o assunto relacionado à sexualidade mais abordado no contexto familiar. Houve associação entre ocorrência de gravidez na adolescência e ausência de conversas sobre sexualidade entre pais e filhos. Destaca-se a necessidade de políticas públicas que atuem com as famílias, incentivando o diálogo entre pais e filhos.

Palavras-chave: Adolescente. Família. Sexualidade.

\begin{abstract}
This study aimed to understand how the theme of sexuality is presented in family context of teenagers of popular groups. Focus groups with girls of two elementary schools from a city in the rural area of Rio Grande do Sul were carried out. Data were analyzed using content analysis. The results reveal that despite the difficulties to address the theme of sexuality, when the subject is approached, it is usually the mothers who do. Teenagers understand that their mothers are more willing to talk to girls, while fathers have an easier time with the boys. The use of condoms is the most discussed issue related to sexuality in the family context. There was an association between the occurrence of teenage pregnancy and the lack of conversation between parents and children. We emphasize the need of public policies that work with families, stimulating dialogue between parents and children.
\end{abstract}

Keywords: Adolescent. Family. Sexuality.

Psicol. Argum. 2014 jan./mar., 32(76), 57-67 


\section{Introdução}

A adolescência é uma etapa importante para a consolidação da personalidade e constituição da identidade adulta, sendo um período de mudanças e descobertas (Aberastury 1981/2007; Blos, 1962/1998; Knobel 1981/2007). Uma das transformações mais significativas deste período é o desenvolvimento e a possibilidade do exercício da sexualidade genital (Rappaport, 1993). Para a psicanálise, a adolescência constitui a etapa final da fase genital, quarta fase do desenvolvimento psicossexual, sendo o avanço rumo à afirmação genital na adolescência a continuidade de um desenvolvimento que foi temporariamente detido durante a latência (Blos, 1962/1998). Assim, na adolescência ocorre o ressurgimento da sexualidade, agora no nível de maturidade genital (Knobel, 1981/2007).

As modificações físicas e sexuais que acontecem neste momento têm um efeito significativo na forma como o adolescente se percebe e se avalia, além de alterarem radicalmente o modo como ele é visto pelos outros. Dessa forma, destaca-se a importância de que a família se ocupe da tarefa de auxiliar este adolescente a lidar com a confusão de pensamentos, sentimentos e comportamentos relativos à sexualidade que se faz presente neste período (Preto, 1995).

O momento atual está fortemente marcado pela temática da sexualidade. 0 adolescente está o tempo todo em contato com uma grande quantidade de estímulos ligados à sexualidade e pode facilmente ter acesso a uma ampla variedade de informações relativas a esse assunto (Cano \& Ferriani, 2000; Predebon, 2002; Valdés, 2005). Desse modo, os pais precisam estar dispostos e preparados para lidar, através de um diálogo aberto, com as dúvidas, curiosidades e inquietações que vão surgindo (Predebon, 2002).

Grande parte dos pais acredita que os professores estão mais preparados do que eles para trabalhar o tema da sexualidade com os adolescentes, delegando, assim, à escola a tarefa de abordar estes assuntos (Cano \& Ferriani, 2000; Valdés, 2005). Porém, percebe-se que, nas escolas, a sexualidade geralmente é abordada priorizando-se seus aspectos biológicos e tratada como sinônimo de genitalidade, desconsiderando-se, assim, as dimensões afetivas e emocionais (Cardoso, Figueiredo \& Pecorari, 2007; Moura, Pacheco, Dietrich, \& Zanella, 2011).
O contexto familiar é considerado por Cano e Ferriani (2000) o lugar ideal para que os assuntos que dizem respeito à sexualidade sejam debatidos e analisados de acordo com os valores e crenças de cada família. Porém, nota-se que, embora a família seja o grupo social que deveria fornecer o suporte emocional adequado, através de um espaço de trocas e comunicação aberta, os pais ainda encontram dificuldade em proporcionar a seus filhos um ambiente onde possam ser discutidas questões relativas à sexualidade (Predebon, 2002). Os pais estão cientes de que os adolescentes experienciam em seu dia a dia situações ligadas à sexualidade, mas aceitar e lidar com estas questões ainda é um desafio (Cano \& Ferriani, 2000).

De acordo com Levisky (1995), essas dificuldades presentes no contexto familiar dizem respeito aos sentimentos vivenciados pelos pais em relação à sexualidade que foram sublimados ou reprimidos e que são revividos no momento atual pela presença da sexualidade dos filhos. Nesse sentido, o autor afirma que muitas atitudes dos pais decorrem de projeções de suas fantasias em relação aos filhos, que "agora não mais vistos com o corpo de criança, mas vividos ora como criança ora com expectativas de respostas adultomorfas". (Levisky, 1995, p. 115).

Assim, salienta-se que nos casos em que a sexualidade do adolescente é negada, ignorada ou rejeitada pelos pais, há maiores chances desse adolescente desenvolver um autoconceito sexual negativo. Além disso, há um aumento da probabilidade de surgirem sentimentos de alienação entre pais e filhos e da ocorrência de comportamentos sexuais de risco (Preto, 1995).

Nesse sentido, destaca-se o estudo de Aquino, Almeida, Araújo e Menezes (2006), que faz parte de uma pesquisa que abrangeu 4634 participantes de 18 a 24 anos, com o objetivo de investigar o comportamento sexual de jovens brasileiros. Constatouse que os índices de gravidez na adolescência entre as mulheres que afirmaram ter sido providas de informações pelos pais ou pela escola foram mais baixos do que entre aquelas que não receberam estas informações. De acordo com os autores, "o modo como são veiculadas as primeiras informações sobre sexo, gravidez e contracepção situa os indivíduos em diferentes perfis de socialização, com consequências para suas trajetórias reprodutivas". (Aquino et al., 2006, p. 322). 
Dessa forma, no que se refere ao tema da sexualidade, os pais devem expor de forma clara e autêntica seus princípios e pontos de vista aos filhos, oferecendo-lhes, assim, um referencial seguro. Além disso, frisa-se a importância de os pais se colocarem à disposição para ouvir e a avaliar a percepção dos filhos sobre estas questões (Levisky, 1995).

Assim, esta pesquisa se apoia no fato de que a sexualidade é uma parte significativa da vivência dos adolescentes, uma vez que ocorre um "redespertar" da sexualidade neste período. Salienta-se que a compreensão do papel dos pais de adolescentes no início de sua vida sexual se constitui um elemento fundamental para expansão do conhecimento e da atuação no campo da saúde sexual e reprodutiva (Borges, Latorre \& Schor, 2007).

A realização desta pesquisa com adolescentes do sexo feminino se justifica pelo fato de que há uma maior preocupação por parte dos pais e da sociedade com relação à sexualidade das meninas do que com os meninos, uma vez que existe o temor de uma gravidez precoce, além da presença de questões culturais, como a ocorrência de um controle maior da sexualidade feminina (Cano \& Ferriani, 2000). Assim,

se, para os meninos, sua sexualidade - genitalidade refere-se a seus 'poderes de macho', à permissão de seu exercício desde cedo e à exposição de seus corpos seminus, sem restrições morais a respeito, [...] para a menina, sua sexualidade significa perigo, risco, ganho e perda (Duque-Arrazola, 1997, p. 379).

Sousa, Fernandes e Barroso (2006) seguem com uma ideia semelhante, afirmando que o tabu sobre a sexualidade aparece mais acentuado no contexto familiar das adolescentes, sendo os pais geralmente mais rígidos com as meninas. Desse modo, o objetivo desde estudo foi compreender, a partir do discurso de adolescentes de grupos populares, como o tema da sexualidade é tratado no contexto familiar.

\section{Método}

\section{Participantes}

A pesquisa em questão foi realizada em duas escolas (Instituições A e B) que atendem crianças e adolescentes em situação de vulnerabilidade na região periférica de uma cidade de médio porte do interior do Rio Grande do Sul. Estas escolas foram escolhidas porque o estudo trata de adolescentes de grupos populares. Participaram do estudo 15 adolescentes do sexo feminino, com idades entre $13 \mathrm{e}$ 16 anos, que frequentavam as instituições na época da realização da pesquisa e que aceitaram o convite para integrar o estudo.

A Instituição A é não governamental, filantrópica e oferece à comunidade - com cerca de 150 crianças e adolescentes em situação de vulnerabilidade - uma escola de ensino fundamental e um projeto de Apoio Socioeducativo em Meio Aberto (ASEMA), por meio de oficinas (arte de rua, dança, coral, informática, escola de futebol, capoeira e teatro) no turno inverso à escola. A Instituição $\mathrm{B}$ é governamental e funciona na modalidade de escola aberta, atendendo alunos de 10 a 18 anos. As principais fontes de encaminhamento dos alunos são os conselhos tutelares, os abrigos e o Centro de Atendimento Socioeducativo (CASE), além de outras escolas. A escola aberta funciona no sistema de etapas, sendo que cada etapa corresponde a duas séries, totalizando assim quatro etapas. A escola atende uma média de 18 a 20 alunos por dia, visto que há uma grande circulação destes. As aulas acontecem pela manhã, e na parte da tarde ocorrem oficinas pedagógicas: padaria, papel reciclado, matemática na cozinha, teatro, cabeleireiro e informática.

\section{Instrumentos e procedimentos}

Esta pesquisa utilizou-se da técnica de grupos focais, a qual é adequada para investigações qualitativas e atendeu aos objetivos deste estudo. Segundo Gaskell (2005), o objetivo do grupo focal é estimular os participantes para que exponham suas ideias e reajam ao que os outros membros do grupo falam. Trata-se de uma "unidade social mínima em operação" (Gaskell, 2005, p. 75). Dessa forma, as ideias e as representações que surgem no grupo são influenciadas pela natureza social da interação grupal em vez de se basearem no ponto de vista individual, como seria em uma entrevista. Além disso, em um grupo, a partir do compartilhamento de experiências, opiniões e sentimentos, produz-se um quadro de articulações que dificilmente seriam realizadas por um único indivíduo. Para Gaskell (2005), o grupo focal é um ambiente holístico, no qual os

Psicol. Argum. 2014 jan./mar., 32(76), 57-67 
Quadro 1 - Dados sociodemográficos das participantes

\begin{tabular}{|c|c|c|c|c|}
\hline & Participante & Idade & $\begin{array}{l}\text { Escolari- } \\
\text { dade }\end{array}$ & $\begin{array}{l}\text { Com quem } \\
\text { mora? }\end{array}$ \\
\hline \multirow{9}{*}{ 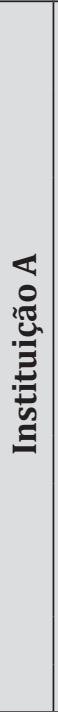 } & A & 14 & $8^{\underline{a}}$ série & $\begin{array}{l}\text { Tio, tia e } \\
\text { prima. }\end{array}$ \\
\hline & V & 14 & $8^{a}$ série & $\begin{array}{l}\text { Pai, mãe e } \\
\text { irmão. }\end{array}$ \\
\hline & K & 14 & 8aa série & $\begin{array}{l}\text { Mãe, } \\
\text { quatro irmãos, } \\
\text { sobrinho e } \\
\text { cunhado. }\end{array}$ \\
\hline & D & 13 & $8^{\text {a }}$ série & $\begin{array}{l}\text { Pai, mãe e } \\
\text { irmãos. }\end{array}$ \\
\hline & $\mathrm{T}$ & 13 & 7a série & Pai e mãe. \\
\hline & E & 13 & 7aㅗ série & $\begin{array}{l}\text { Mãe, irmãs e } \\
\text { cunhado. }\end{array}$ \\
\hline & $\mathrm{R}$ & 13 & 7ạ série & Pai e mãe. \\
\hline & $\mathrm{F}$ & 13 & 7ạ série & Avô, avó e tia. \\
\hline & $S$ & 13 & 7ª série & Avó. \\
\hline \multirow{5}{*}{ 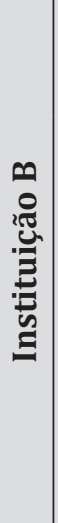 } & G & 15 & $3^{\underline{a}}$ etapa & $\begin{array}{l}\text { Pai, mãe, } \\
\text { quatro irmãos } \\
\text { e duas irmãs. }\end{array}$ \\
\hline & $\mathrm{N}$ & 13 & $3^{\underline{a}}$ etapa & $\begin{array}{l}\text { Pai e dois } \\
\text { irmãos. }\end{array}$ \\
\hline & $\mathrm{J}$ & 16 & $3^{\underline{a}}$ etapa & $\begin{array}{l}\text { Companheiro e } \\
\text { filho do compa- } \\
\text { nheiro. }\end{array}$ \\
\hline & $\mathrm{L}$ & 14 & $4^{\mathrm{a}}$ etapa & $\begin{array}{l}\text { Mãe, três } \\
\text { irmãos e } \\
\text { companheiro. }\end{array}$ \\
\hline & $\mathrm{C}$ & 14 & $4^{\mathrm{a}}$ etapa & $\begin{array}{l}\text { Mãe e cinco } \\
\text { irmãos. }\end{array}$ \\
\hline
\end{tabular}

Fonte: As autoras.

participantes consideram as opiniões dos outros na formação de seus pontos de vista e discutem tanto suas próprias experiências quanto as alheias.

A coleta de dados foi feita a partir de três grupos focais, sendo dois realizados na Instituição A e um na Instituição B. Cada grupo focal contou com a participação de cinco adolescentes. As participantes da Instituição A integraram o estudo após convite realizado pela orientadora educacional da escola, já na Instituição B, participaram do grupo o total de adolescentes presentes na escola no dia da realização da pesquisa.

Realizou-se um encontro com cada grupo focal, utilizando-se os seguintes eixos norteadores: (1) o que vem à cabeça quando se pensa em sexualidade?; (2) como é falar sobre sexualidade?; (3) na família de vocês se fala sobre sexualidade?; (4) com quais membros da família costumam conversar sobre sexualidade?; (5) que tipo de assunto relacionado à sexualidade é conversado?; (6) quais são as barreiras e dificuldades encontradas para que haja esse tipo de conversa na família? Os encontros tiveram a duração aproximada de uma hora e 15 minutos e foram gravados e posteriormente transcritos para a análise dos dados.

\section{Análise dos dados}

Os dados foram analisados através do método de Análise de Conteúdo, como proposto por Bardin (1977). Para se chegar às categorias, os grupos foram analisados de forma individual e depois em conjunto, partindo-se para os elementos presentes nos mesmos, considerando a força discursiva, os sentimentos manifestados e os silêncios ou conflitos em relação à temática.

Neste artigo foram incluídos os eixos norteadores 3,4 e 5 , os quais deram origem às seguintes categorias: (a) o papel dos pais na abordagem da sexualidade com adolescentes; (b) os assuntos referentes à sexualidade mais abordados na família; (c) diálogos sobre sexualidade na família e gravidez na adolescência.

\section{Consideracões éticas sobre o trabalho}

Após os diretores das escolas assinarem os Termos de Autorização Institucional, o projeto de pesquisa foi submetido e aprovado pelo Comitê de Ética da instituição de ensino superior à qual as pesquisadoras estão vinculadas (Processo no 23081.005730/2011-19, Certificado de Apresentação para Apreciação Ética no 0076.0.243.000-11).

O Termo de Consentimento Livre e Esclarecido foi assinado pelas participantes após serem esclarecidos os procedimentos a serem realizados, os objetivos e a justificativa da pesquisa, tal como previsto na aprovação pelo Comitê de Ética em Pesquisa da instituição responsável. Destaca-se que embora as participantes deste estudo fossem adolescentes, o TCLE foi assinado por estas, considerando-se que estas poderiam compreender os objetivos e a justificativa do estudo, estando, portanto, em condições 
de assentir sua participação. Esta consideração encontra-se embasada nas Diretrizes Internacionais para Pesquisa Biomédica em Seres Humanos, Diretriz no 14 (Gallagher, 2004). Além disso, tal diretriz aponta para alguns estudos que incluem pesquisa das crenças e do comportamento adolescente em relação à sexualidade ou referentes à violência doméstica e ao abuso. Para tais pesquisas, pode-se prescindir da autorização dos pais se, por exemplo, o conhecimento por parte deles poderia levá-los a questionar ou intimidar o adolescente.

\section{Resultados e discussão}

\section{0 lugar dos pais na construção do diálogo sobre sexualidade com adolescentes}

As adolescentes participantes do estudo afirmaram que o assunto sexualidade é pouco tratado na família e que a maioria dos pais não dá abertura para que haja diálogo em relação a esse tema. "Com os pais a gente não tem coragem... A gente sabe que eles não vão falar. A gente não chega neles..."(F, 13 anos); "Pra mim não falam nada." (C, 14 anos).

Apesar das dificuldades e limitações existentes para se abordar a temática da sexualidade, em todos os grupos focais as adolescentes apontaram que, quando este assunto é abordado, geralmente são as mães que o fazem, embora as participantes reconheçam que estas nem sempre o fazem de forma satisfatória, como se pode evidenciar no depoimento a seguir:

L: Minha mãe me disse: "Me avisa quando tu perder a tua virgindade, que eu vou te levar no posto".

Moderador: E ela fez isso?

L: Fez, só que ela me levou a pau. Não foi do jeito que eu pensei que ela fosse fazer. Ela disse: "Quando tu fizer, tu chega em mim e me conta". Eu cheguei na minha mãe com medo, mas cheguei. Como eu digo pra J e digo pra todo mundo: eu sou daquelas que falam. Eu não escondo, eu falo. Eu não conseguia olhar para a minha mãe de saber que eu tava mentindo pra ela. E ela dizia: "Não mente pra mim, porque eu não menti pra ti". Aí quando eu perdi, eu falei: "Mãe, sabe aquilo que tu me disse?" E ainda fazia três dias que a minha mãe tinha conversado comigo. "Sabe aquilo que tu falou comigo sobre sexo?” E ela: "Hã?” "Eu perdi minha virgindade". Minha mãe me deu dois tapas, me pegou pelo braço e, de manhã, me levou no posto. Minha mãe chegou no posto, bateu em cima da mesa da secretária e disse bem assim: "Minha filha perdeu a virgindade. Quero remédio e camisinha". Minha mãe foi bem grossa, mas acho que foi bom para eu aprender que eu tenho que me preparar quando eu vá fazer, que eu tenho que me cuidar (L, 14 anos).

Estudos já realizados constataram que quando há algum grau de diálogo sobre sexualidade no âmbito familiar, este se dá majoritariamente com a mãe (Pick \& Palos, 1995; Predebon, 2002; Brandão, 2004; Aquino et al., 2006; Borges, Nichiata \& Schor, 2006; Bozon \& Heilborn, 2006; Borges et al., 2007; Gubert \& Madureira, 2008). Enquanto isso, o pai costuma apresentar menor habilidade para o diálogo. Muitos são distantes do dia a dia dos filhos, possuem um distanciamento relacional ou não estão disponíveis para negociações familiares. Tais fatores dificultam que haja uma comunicação entre eles voltada para o tema da sexualidade (Brandão, 2004).

Para as meninas, é muito difícil iniciar um diálogo sobre sexualidade com o pai. Esta questão pode ser visualizada no trecho de um dos grupos: "K: Tipo, imagina tu chegar: 'Ó, pai, vamos conversar sobre sexo aí. A: É... Fica meio sem jeito... V: 'Eu queria conversar com o senhor sobre isso...'. Ainda mais com o pai, né..." (K, A, V, todas com 14 anos).

As meninas apontam que o pai geralmente não é aberto para este tipo de conversa: "Meu pai não fala nada. Ele trabalha de dia, chega de noite e vai dormir." (N, 13 anos); "Se eu conversar isso com meu pai... [Risos] Ele não deixa eu falar..." (A, 13 anos); "Meu pai não gosta que fale de sexo em casa. [...] Ele fala bem assim: 'Se a gente fala de sexo é porque a gente é tarado'. Aí não dá pra falar nada na frente dele. Ele xinga, ele coloca a boca..." (G, 15 anos)

Nota-se na fala a seguir que o pai da adolescente parece ter dificuldades em lidar com o tema da sexualidade e procura evitar o assunto, mas quando essa fala acontece, não é de uma maneira adequada:

Quando eu perdi minha virgindade, eu fui morar com meu ex e depois voltei pra casa dos meus pais. Daí qualquer coisinha ele [pai] fala: "Ah, depois que deu o rabo, voltou pra casa". Quando eu saí de casa, foi minha mãe que me mandou embora, não foi porque eu quis [...]. Daí um dia que eu tava doente e fui buscar

Psicol. Argum. 2014 jan./mar., 32(76), 57-67 
minha carteira de identidade em casa, ele falou bem assim: "Já deu bastante o rabo, por isso que tá doente." (G, 15 anos).

Uma pesquisa realizada por Jones (2010) mostra que dois terços das adolescentes entrevistadas nunca falaram sobre sexualidade com o pai. Diante do fato de que a mãe obtém maior preferência para se falar sobre estas questões, Predebon (2002) lança hipóteses para explicar o porquê deste fato. Primeiramente, pode-se pensar que isto sinaliza um vínculo saudável entre mãe e filha, o que possibilita que a adolescente se sinta à vontade para expor sentimentos e dúvidas tão íntimos às mães. Outra hipótese aponta para o lugar tradicionalmente ocupado pelo pai fora do âmbito doméstico, relacionado ao estereótipo sociocultural que prevê que ele trabalhe fora e garanta o sustento da família. Dessa forma, o pai não teria tempo para se envolver com os filhos e conversar sobre esse tipo de assunto. Tal situação acarreta uma sobrecarga da mãe no meio familiar, a qual, além de ter várias outras responsabilidades dentro e fora da família, ainda tem a tarefa de conversar sozinha com os filhos adolescentes sobre sexualidade. Além disso, Predebon (2002) levanta a hipótese de que o envolvimento com questões de ordem emocional e relacionadas ao bem-estar psicológico da família ainda estaria mais associado à figura da mãe, o que faria que os filhos tivessem preferência por ela no momento de conversar.

As meninas entendem que é mais fácil conversar com a mãe do que com o pai, pois a mãe já passou pelas experiências que elas estão passando, como a ocorrência da menstruação, e assim saberia mais sobre "coisas de menina". Já o pai, segundo as adolescentes, estaria mais apto para falar com os meninos, pelo fato de que ele teria conhecimento das "regras de guri", pois "ele já foi guri um dia" (K, 14 anos). Estes aspectos são evidenciados nos seguintes trechos:

Se for guria, vai ser a mãe, porque quando tu começa a menstruar, a mãe te dá aquela base antes. Ou o pai, depende do pai, quando o guri começa a gostar de uma guria ou começa a ficar com as gurias... Aí depende disso. (T, 13 anos).

É que a mãe é mulher, entendeu? Tu tem o mesmo corpo que ela, então ela vai te aconselhar, vai te explicar melhor do que teu pai. (S, 13 anos).
O estudo de Bozon e Heilborn (2006) chama atenção para as diferenças de gênero na socialização referente à sexualidade. Para as adolescentes, a mãe é considerada uma das principais fontes de informações referentes à gravidez e à contracepção, enquanto o papel do pai diante destas questões é praticamente nulo. Já para os meninos, o pai é considerado uma das fontes de informação.

Além da presença ou ausência no diálogo sobre a sexualidade, cabe destacar também que as formas como se apresentam os discursos da mãe e do pai são diferentes. Uma pesquisa realizada por Valdés (2005) revelou que o pai, em vez de informar de forma coerente a adolescente, assume uma postura silenciosa diante das dúvidas da filha e de reprimenda perante suas amizades. Além disso, nota-se no pai a transmissão de um discurso que enfatiza para a adolescente os riscos das experiências vinculadas à sexualidade e, principalmente, a ameaça que os homens representam. 0 estudo de Valdés (2005) também mostrou que pais e padrastos possuem mais dificuldades de aceitação da sexualidade das filhas do que as mães.

Nesse sentido, Sousa et al. (2006) afirmam que o tabu sobre a sexualidade aparece mais acentuado no contexto familiar das adolescentes, assim, nota-se que os pais geralmente são mais rígidos com as meninas. Percebe-se uma maior preocupação por parte dos pais e da sociedade com relação à sexualidade das meninas do que com os meninos, uma vez que existe o temor de uma gravidez precoce, além da presença de questões culturais (Cano \& Ferriani, 2000).

\section{Assuntos mais abordados na família referentes à sexualidade}

As adolescentes enfatizaram a prevenção, com destaque para uso da camisinha, como o assunto mais abordado no contexto familiar em relação ao tema da sexualidade. Esta questão é ilustrada nas falas a seguir:

O máximo que a mãe me fala é: "Se tu for fazer alguma coisa, tu usa camisinha" [...] A senhora camisinha... [risos] É, o que eles mais falam... Se prevenir... (K, 14 anos)

Ela [avó] começou a falar comigo a partir dos 13 [...]. Daí ela fala que tem que se prevenir, que tem que se cuidar. (S, 13 anos). 
De acordo com Jones (2010), as conversas sobre sexualidade entre pais e adolescentes ficam centralizadas em recomendações sobre "cuidar-se" de gravidez e doenças, enquanto as experiências sexuais dos filhos recebem pouca atenção. Segundo Brandão (2004), as conversas sobre sexualidade na família mostram-se ainda pouco explícitas. Raramente as famílias conseguem tratar deste assunto com os filhos de forma direta, direcionada para as vivências dos mesmos. Em geral, os assuntos são abordados indiretamente. Por exemplo, fala-se de maneira genérica da sexualidade, dos métodos anticoncepcionais e da AIDS como se estes elementos não estivessem próximos das experiências dos filhos. Muitas vezes estas conversas são apoiadas em fatores externos, como na experiência de outras pessoas, em reportagens, filmes, entre outros, ou seja, a experiência do adolescente não é levada em consideração (Brandão, 2004). 0 trecho a seguir está relacionado a estes aspectos:

Quando eu morava com minha mãe, ela conversava bastante comigo... [Falava que] quando eu perdesse, era para eu chegar nela e falar, porque ela ia me levar no posto... [Falava] que era para eu me cuidar, para eu ir com a pessoa certa, com um trabalhador, como toda mãe diz. (N, 13 anos).

A fala de $\mathrm{N}$ coincide com os dados da pesquisa de Dias e Gomes (2000), que mostra que os pais não conseguem transmitir informações de forma adequada, o que ocorre geralmente de maneira fragmentada, limitando-se a recomendações como "te cuida" e "avise quando chegar a hora".

Apesar do assunto gravidez não ter sido claramente referido como um dos assuntos mais frequentes no diálogo familiar, pôde-se perceber nos grupos que a preocupação a respeito do uso de camisinha estaria diretamente relacionada ao tema da gravidez por meio da forma como as participantes se referem às atitudes dos pais quando estes sinalizam o cuidado que elas devem ter e a importância da prevenção. Assim, fica evidente que a gravidez é o grande fantasma da sexualidade (Valdés, 2005; Jones, 2010).

\section{Diálogos sobre sexualidade na família e gravidez na adolescência}

A questão da gravidez na adolescência é um fenômeno complexo que ainda levanta inúmeros questionamentos. Muitos autores consideram-na um problema de saúde pública (Brandão \& Heilborn, 2006; Silva \& Tonete, 2006; Trindade \& Menandro, 2002), outros afirmam que esse enfoque da gravidez na adolescência como um problema provoca lacunas na compreensão do tema, mostrando-se insuficiente para explicar a complexidade do fenômeno (Dadoorian, 2003; Moreira, 2003; Moura et al., 2011). De acordo com Moreira (2003), ao se considerar a gravidez na adolescência unicamente como um problema, desenvolvem-se barreiras relacionadas tanto à possibilidade de reflexão teórica quanto às intervenções que podem ser realizadas com adolescentes através de projetos de saúde e de educação.

Destaca-se que diante da falta de ideais, objetivos de vida e perspectivas para o futuro, muitas adolescentes acabam engravidando e tornando a gravidez seu projeto de vida (Dadoorian, 2003; Santos \& Carvalho, 2006). Dessa forma, para muitas adolescentes de grupos populares, a maternidade pode se tornar o papel social mais importante por elas desempenhado (Dadoorian, 2003). Assim, entre tantos aspectos vinculados a essa questão complexa que é a gravidez na adolescência, procurou-se focar neste trabalho a relação entre os diálogos sobre sexualidade no contexto familiar e a ocorrência de gravidez na adolescência.

De acordo com Dias e Gomes (1999, p. 81), muitas vezes "a gravidez na adolescência denuncia, de um modo contundente, um fenômeno que costuma ser ignorado no ambiente familiar - a sexualidade do adolescente". Assim, para os autores, a falta de conversas sobre sexualidade no âmbito familiar pode se tornar notável apenas após o episódio de gravidez de uma filha.

Nesse sentido, pode haver uma abertura maior dos pais para este tipo de diálogo após o episódio de gravidez de uma filha. Este fenômeno é descrito por J (16 anos), a qual engravidou aos 13 anos, mas teve um aborto espontâneo no terceiro mês de gestação:

J: Eu nunca conversei sobre sexo com a minha mãe. Eu sempre tive vergonha. Só que depois que aconteceu tudo aquilo [gravidez] eu comecei a me abrir com ela. Porque ela sabe o que a gente passou, foi sofrimento, foi tristeza...

Moderador: Mas antes de engravidar tu nunca conversou sobre sexualidade com a tua mãe?

Psicol. Argum. 2014 jan./mar., 32(76), 57-67 
J: Não, nunca, por isso. Depois que a mãe foi me explicar. Antes, a mãe não explicava, só que eu tinha medo de contar pra mãe. Que a mãe ela não é uma pessoa assim de aceitar. Claro, ela aceita, mas ela é meio traumatizada: "Não, não faz, não é certo, eu não vou te dizer"

Conforme Dias e Gomes (1999), muitos pais não falam sobre sexualidade com suas filhas antes de um episódio de gravidez. Geralmente estes pais presumem que as adolescentes estejam mais bem informadas do que eles.

As meninas associaram a ocorrência de gravidez na adolescência à falta de conversas sobre sexualidade entre pais e filhos, o que pode ser visualizado nas seguintes falas:

Porque se falasse, os jovens de hoje teriam mais consciência sobre o que é isso. Não teria várias jovens grávidas por aí, de 13, 14 anos... (L, 14 anos)

E se os pais não conversam, começam a prender em casa. Tem uma hora que elas vão ter vontade e vão acabar fazendo escondido, algumas acabam "pegando uma barriga”, como dizem, por falta de conversas. Às vezes, por falta de conversa com a família, em casa. (A, 14 anos)

Gravidez na adolescência, iniciação sexual precoce e utilização de métodos contraceptivos têm sido descritos na literatura como questões que podem ser fortemente influenciadas pelos diálogos sobre sexualidade entre pais e filhos (Pick \& Palos, 1995; Dias \& Gomes, 2000; Aquino et al., 2006; Bozon \& Heilborn, 2006; Sousa et al., 2006). Pick e Palos (1995) realizaram um estudo no México que teve como objetivo mostrar o papel que a família exerce na vida sexual dos adolescentes. 0 estudo constatou que as meninas que conversam com frequência sobre sexo com suas mães têm menor probabilidade de iniciar a vida sexual precocemente e engravidar durante adolescência e mais chances de utilizar algum método contraceptivo. Sousa et al. (2006), neste mesmo sentido, afirmam que se o adolescente encontra na família um ambiente aberto para o diálogo sobre sexualidade, existe menos chance de ocorrer episódios de gravidez na adolescência e infecção pelo vírus HIV.

0 estudo de Bozon e Heilborn (2006) verificou que as adolescentes que conversaram com suas mães sobre menstruação e foram orientadas quanto aos métodos contraceptivos apresentaram maior probabilidade de usar proteção em sua primeira relação sexual quando comparadas às adolescentes que não tiveram esse tipo de orientação. As conversas entre mãe e filha sobre menstruação constituem-se em uma oportunidade de transmissão de informações sobre prevenção. Assim, quanto mais cedo estas conversas acontecem, menores as chances de ocorrência de gravidez na adolescência (Aquino et al., 2006).

Neste sentido, Valdés (2005) afirma que o resultado desse diálogo é evidente no momento em que as adolescentes resolvem iniciar a prática de relações sexuais. Muitas jovens relataram terem se recordado das recomendações dos pais na ocasião em que se iniciavam sexualmente. De forma semelhante, esta ideia se fez presente durante um dos grupos focais, como mostra o trecho a seguir:

$\mathrm{Na}$ hora que tu for perder ali, tu já sabe que a tua mãe te explicou, tua mãe te falou como é que é. Aí tu vai fazer tudo certinho para não correr o risco de não acontecer nada que prejudique no amanhã (K, 14 anos).

Em contraponto a isso, Tavares (1996) aponta que muitos pesquisadores constataram que a maioria das adolescentes que engravidam, mesmo aquelas pertencentes às camadas mais pobres da população, é bem informada e tem conhecimento dos métodos contraceptivos. Uma pesquisa realizada por Dadoorian (2003) com adolescentes grávidas de grupos populares mostrou que todas tinham conhecimento de que praticar sexo sem a utilização de contraceptivo poderia provocar gravidez, porém isso não determinou que elas fizessem uso desses métodos. Assim, às vezes as adolescentes têm conhecimento dos riscos e das formas de evitar a gravidez, mas não põem isso em prática e geralmente não sabem explicar o que as leva a agir dessa maneira (Tavares, 1996). Nesse sentido, Dadoorian (2003) afirma que as causas da gravidez na adolescência não se relacionam exclusivamente à desinformação sobre questões sexuais, mas também ao desejo da adolescente de ter um filho, talvez a fim de testar sua feminilidade a partir da comprovação de seu potencial reprodutivo.

A história familiar de gravidez na adolescência tem sido descrita na literatura como um dos fatores associados à ocorrência de gravidez em 
adolescentes (Preto, 1995; Persona, Shimo \& Tarallo, 2004; Valdés, 2005; Aquino et al., 2006). Desse modo, se o diálogo pode diminuir a incidência da gravidez na adolescência, o silêncio associado ao histórico de gravidez adolescente no contexto familiar parece constituir um elemento potencial para sua repetição. Durante os grupos focais, pôde-se perceber que grande parte das meninas tinha algum familiar (mãe, irmã ou avó) que engravidou durante a adolescência.

Na verdade, minha mãe ganhou o primeiro filho dela com 15. É que a minha mãe disse que com ela também aconteceu isso porque a mãe dela não chegou... Ela perdeu a mãe cedo, perdeu o pai cedo [...]. Eu acho que nessa parte nunca teve ninguém para cobrar dela. Ela nunca teve ninguém para falar com ela sobre isso (K, 14 anos).

Como Duque-Arrazola (1997, p. 387) afirma em seu estudo: "As mães afirmam não quererem que aconteça o que sucedeu com elas quando se perderam, quando deixaram de ser virgens, quando engravidaram sem saber ou sem querer". Neste mesmo sentido, a adolescente $S$ (13 anos) afirma:

Minha avó, que eu chamo de mãe, é mais aberta porque ela já passou por certas dificuldades na vida dela e tem medo que aconteça alguma coisa comigo. Ela fala: "Olha, o dia que tu arrumar um namorado, me fala, conversa comigo, se abre", porque... Ela parece que tem um medo. Ela me contou a história dela, e eu entendo que ela tem medo que aconteça alguma coisa comigo [...] porque a minha mãe me teve com 17 anos. E ela não tem condições de me criar.

Percebe-se no discurso dos familiares o temor da repetição da história de gravidez na adolescência, o que fica evidenciado também nas seguintes falas das adolescentes:

Minha mãe teve eu e minha irmã, eu com 15 e minha irmã com 16. Então por isso que a minha avó sempre foge do assunto, porque acha que se eu ficar sabendo agora, eu vou fazer a mesma coisa que a minha mãe. (F, 13 anos).

Só que a minha avó me fala de sexualidade. Daí ele [pai] me fala: “É, a tua avó só fala besteira. Ela fala essas coisas e quando vê, tu vai seguir o mesmo exemplo dela" (S, 13 anos).
Nota-se que a avó de F evita falar sobre sexualidade com a neta por medo que o acesso à informação a estimule a ter relações sexuais, o que poderia resultar em uma gravidez, ocorrendo assim a repetição da história materna.

\section{Considerações finais}

Pôde-se notar através deste estudo que a mãe assume um papel importante quando se trata da abordagem do tema da sexualidade, uma vez que as meninas referiram-na como a pessoa da família mais aberta para conversar sobre este assunto. Enquanto isso, o pai é visto pelas meninas como alguém indisponível para o diálogo relativo à sexualidade, tendo este mais facilidade com os meninos.

Observou-se a partir do discurso das adolescentes que os pais ainda não conseguem tratar deste assunto com as adolescentes de forma direta, direcionada para as vivências das mesmas. Assim, quando os pais abordam o tema com as filhas, geralmente o fazem sinalizando principalmente para o uso da camisinha e para a importância dos cuidados para evitarem doenças e gravidez.

Considerando que o uso da camisinha é o assunto relacionado à sexualidade mais abordado no contexto familiar, infere-se que o destaque dado a este assunto pode estar diretamente associado ao temor da gravidez das filhas, uma vez que esta se constitui em uma das grandes preocupações dos pais, principalmente quando já existe um histórico familiar de gravidez na adolescência.

Evidenciou-se que as adolescentes atribuem grande importância às conversas sobre sexualidade no contexto familiar, uma vez que destacaram que a ocorrência desses diálogos pode contribuir para diminuir a incidência da gravidez na adolescência, além de relatarem terem se recordado das recomendações dos pais na ocasião de sua iniciação sexual.

Salienta-se que a ausência de abertura para o diálogo a respeito do tema da sexualidade distancia pais e filhos e pode gerar um sentimento de desamparo nos adolescentes, dado que esse período é marcado por dúvidas, angústias e muitas transformações no âmbito da sexualidade.

0 tema tem sido lançado na sociedade de maneira geral, por vezes até banalizado, o que pode muitas vezes confundir os pais com relação ao saber dos filhos sobre o assunto. Frisa-se que apesar do fato

Psicol. Argum. 2014 jan./mar., 32(76), 57-67 
de a sexualidade estar fortemente presente em diferentes contextos, esta presença ainda não acalmou as angústias das adolescentes com relação ao tema e, nesse sentido, os pais não estariam liberados de sua importante tarefa no tratamento do tema.

Diante do fato de que a sexualidade ainda é um assunto pouco abordado no contexto familiar e da importância de que se efetive o diálogo com os adolescentes sobre este tema, destaca-se a necessidade da construção e implementação de políticas públicas específicas que atuem com as famílias, incentivando o diálogo entre pais e filhos e ajudando os pais a lidar melhor com as demandas dos adolescentes referentes à temática da sexualidade. É fundamental que se crie um ambiente de confiança entre pais e filhos, no qual os adolescentes possam expor suas dúvidas e angústias e receber informações e orientações sobre o assunto. Assim, espera-se que os resultados aqui expostos e discutidos possam de alguma forma servir de apoio, estímulo e orientação para a criação de ações de prevenção e promoção da saúde do adolescente.

\section{Referências}

Aberastury, A. (2007). 0 adolescente e a liberdade. In A. Aberastury \& M. Knobel (Orgs.). Adolescência normal: um enfoque psicanalítico (pp. 13-23). Porto Alegre: Artmed. (Obra original publicada em 1981).

Aquino, E. M. L., Almeida, M. da C., Araújo, M. J., \& Menezes, G. (2006). Gravidez na adolescência: a heterogeneidade revelada. In M. L. Heilborn, E. M. L. Aquino, M. Bozon, \& D. R. Knauth (Orgs.). O aprendizado da sexualidade: reprodução e trajetórias sociais de jovens brasileiros (pp. 309-360). Rio de Janeiro: Garamond e Fiocruz.

Bardin, L. (1977). Análise de conteúdo. Lisboa: 70.

Blos, P. (1998). Adolescência: uma interpretação psicanalítica. São Paulo: Martins Fontes. (Obra original publicada em 1962).

Borges, A. L. V., Latorre, M. R. D. O., \& Schor, N. (2007). Fatores associados ao início da vida sexual de adolescentes matriculados em uma unidade de saúde da família da zona leste do município de São Paulo, Brasil. Cad. Saúde Pública, 23(7), 1583-1594.
Borges, A. L. V., Nichiata, L. Y. I., \& Schor, N. (2006). Conversando sobre sexo: a rede sociofamiliar como base de promoção da saúde sexual e reprodutiva de adolescentes. Rev. Latino-am. Enfermagem, 14(3), 422-427.

Bozon, M., \& Heilborn, M. L. (2006). Iniciação à sexualidade: modos de socialização, interações de gênero e trajetórias individuais. In M. L. Heilborn, E. M. L. Aquino, M. Bozon, \& D. R. Knauth (Orgs.). $O$ aprendizado da sexualidade: reprodução e trajetórias sociais de jovens brasileiros (pp. 155-206). Rio de Janeiro: Garamond e Fiocruz.

Brandão, E. R. (2004). Iniciação sexual e afetiva: exercício da autonomia juvenil. In M. L. Heilborn (Org.). Família e sexualidade (pp. 63-86). Rio de Janeiro: FGV.

Brandão E. R., \& Heilborn M. (2006). Sexualidade e gravidez na adolescência entre jovens de camadas médias do Rio de Janeiro, Brasil. Cadernos de saúde pública, 22(7), 1421-1430.

Cano, M. A. T., \& Ferriani, M. G. C. (2000). A família frente à sexualidade dos adolescentes. Acta. Paul. Enf., 13(1), 38-46.

Cardoso, L. R. D., Figueiredo, T. F. B., Pecorari, E. P. D. N. (2007). Escolas do ensino fundamental estão desenvolvendo programa de orientação sexual? Psicol. Argum., 25(51), 385-391.

Dadoorian, D. (2003). Gravidez na adolescência: um novo olhar. Psicologia Ciência e Profissão, 23(1), 84-91.

Dias, A. C. G., \& Gomes, W. B. (1999). Conversas sobre sexualidade na família e gravidez na adolescência: a percepção dos pais. Estudos de Psicologia, 4(1), 79-106.

Dias, A. C. G., \& Gomes, W. B. (2000). Conversas, em família, sobre sexualidade e gravidez na adolescência: percepção das jovens gestantes. Psicol. Reflex. Crit., 13(1), 109-125.

Duque-Arrazola, L. S. (1997). O cotidiano sexuado de meninos e meninas em situação de pobreza. In F. R. Madeira (Org.). Quem mandou nascer mulher? Estudos sobre crianças e adolescentes pobres no Brasil (pp. 343-402). Rio de Janeiro: Record/Rosa dos Tempos. 
Erikson, E. H. (1972). Identidade, juventude e crise. Rio de Janeiro: Zahar.

Gallagher, J. (2004). Diretrizes Éticas Internacionais para Pesquisa Biomédica em Seres Humanos. São Paulo: Loyola.

Gaskell, G. (2005). Entrevistas individuais e grupais. In M. W. Bauer \& G. Gaskell (Orgs.). Pesquisa qualitativa com texto, imagem e som: um manual prático (pp. 6489). Petrópolis: Vozes.

Gubert, D., \& Madureira, V. S. F. (2008). Iniciação sexual de homens adolescentes. Ciência \& Saúde Coletiva, 13(Supl. 2), 2247-2256.

Jones, D. E. (2010). Diálogos entre padres y adolescentes sobre sexualidad: discursos morales y médicos en la reproducción de las desigualdades de género. Interface - Comunic., Saude, Educ., 14(32), 171-182

Knobel, M. (2007). 0 adolescente e a liberdade. In A. Aberastury, \& M. Knobel (Orgs.). Adolescência normal: um enfoque psicanalítico (pp. 24-62). Porto Alegre: Artmed. (Obra original publicada em 1981).

Levisky, D. L. (1995). Adolescência: reflexões psicanalíticas. Porto Alegre: Artes Médicas.

Moreira, M. I. C. (2003). Laços familiares e laços geracionais: uma reflexão sobre a gravidez entre mulheres adolescentes. In S. M. G. Sousa. (Org.). Infância e adolescência: múltiplos olhares (pp. 113-143). Goiânia: UCG.

Moura, A. F. M., Pacheco, A. P., Dietrich, C. F., \& Zanella, A. V. (2011). Possíveis contribuições da psicologia para a educação sexual em contexto escolar. Psicol. Argum. 29(67), 437-446.

Persona, L., Shimo, A. K. K., \& Tarallo, M. C. (2004). Perfil de adolescentes com repetição da gravidez atendidas num ambulatório de pré-natal. Rev Latino-am Enfermagem, 12(5), 745-750.

Pick, S., \& Palos, P. A. (1995). Impact of the family on the sex lives of adolescents. Adolescence, 30(119), 667-675.
Predebon, J. C. (2002). Conversando sobre sexo na família com filhos adolescentes. In A. Wagner. (Org.). Família em cena: tramas, dramas e transformações (pp. 159171). Petrópolis: Vozes.

Preto, N. G. (1995). Transformações do sistema familiar na adolescência. In B. Carter, \& M. McGoldrick (Orgs.). As mudanças no ciclo de vida familiar: uma estrutura para a terapia familiar. Porto Alegre: Artmed.

Rappaport, C. R. (1993). Adolescência: abordagem psicanalítica. São Paulo: EPU.

Santos, A., \& Carvalho, C. V. (2006). Gravidez na adolescência: um estudo exploratório. Boletim de Psicologia, 54(125), 135-151.

Silva, L., \& Tonete, V. L. P. (2006). A gravidez na adolescência sob a perspectiva dos familiares: compartilhando projetos de vida e cuidado. Rev Latino-am Enfermagem, 14(2), 199-206.

Sousa, L. B., Fernandes, J. F. P., \& Barroso, M. G. T. (2006). Sexualidade na adolescência: análise da influência de fatores culturais presentes no contexto familiar. Acta. Paul. Enferm., 19(4), 408-413.

Tavares, E. (1996). Mãe menininha. In A. I. Corrêa (Org.). Mais tarde é agora! Ensaios sobre a adolescência (pp. 101-115). (Coleção psicanálise da criança, v. 1, n. 8). Salvador: Álgama.

Trindade, Z. A., \& Menandro, M. C. S. (2002). Pais adolescentes: vivência e significação. Estudos de Psicologia, $7(1), 15-23$.

Valdés, T. (2005). Socialização em sexualidade no Chile: adolescentes de camadas populares urbanas. In M. L. Heilborn, L. F. D. Duarte, C. Peixoto, \& M. L. de Barros (Orgs.). Sexualidade, família e ethos religioso (pp. 315-342). Rio de Janeiro: Garamond.

Psicol. Argum. 2014 jan./mar., 32(76), 57-67 